\title{
Kewadatan Lesmana dalam Sastra Tulis dan Pertunjukan Wayang
} (The Celibacy of Lesmana in Written Literature and Wayang Performances)

\author{
Suprihana, Udreka \\ Jurusan Seni Pedalangan, Fakultas Seni Pertunjukan Indonesia, \\ Institut Seni Indonesia Yogyakarta \\ Email:wayangwahyukita@gmail.com,ki.udrekka@gmail.com
}

\begin{abstract}
This paper discusse s Lesmana's celibacy practices in written texts and play of wayang purwa performance. For the purpose, the writer tries to see the intertextual relationship beween written texts of Serat Rama Jasadipoera and Novel Anak Bajang Menggiring Angin, and a play of Banjaran Rahwono by Ki Timbul Hadi Prayitno. Qualitative descriptive method is used for analysis. The finding shows that the concept of Lesmana's celibacy practices in the three texts does not change.
\end{abstract}

Key words: celibacy practices, Lesmana, intertextual, written literature, oral literature

\begin{abstract}
Abstrak
Tulisan ini membahas kewadatan Lesmana dalam teks tulis dan teks lakon pertunjukan wayang kulit purwa. Tulisan ini juga membahas hubungan intertekstual teks tersebut khususnya tentang konsep wadat Lesmana. Data yang digunakan ialah Serat Rama Jasadipoera, Novel Anak Bajang Menggiring Angin Sindhunata, dan lakon Banjaran Rabwono Ki Timbul Hadi Prayitno. Konsep intertekstual digunakan sebagai kerangka teori. Metode analisis data menggunakan metode deskriptif kualitatif. Temuan dari penelitian ini ialah konsep wadat Lesmana dalam ketiga teks tidak mengalami penyimpangan atau perubahan.
\end{abstract}

Kata kunci: wadat, Lesmana, intertekstual, sastra tulis, sastra lisan

\section{Pengantar}

Kata wadat atau selibat, di abad 21 ini rupa-rupanya sudah asing dari pendengaran kita. Dua kata ini ketenarannya kalah jauh dengan kata wedding, selingkuh, WIL (wanita idaman lain), PIL (pria idaman lain), samara (sakinah mawaddah wa rahmah). Anak-anak dan remaja bahkan tidak tahu arti dua kata tersebut. Meskipun dalam kenyataannya di masyarakat, ada orang-orang yang menjalani hidup selibat atau wadat.
Kata wadat dalam bahasa Jawa artinya ora nglakoni bebojoan 'tidak berumah tangga / tidak beristeri' (Poerwadarminta \& dkk., 1939, p. 652). Sedangkan kata selibat artinya pranata yang menentukan bahwa orang-orang dalam kedudukan tertentu tidak boleh kawin (Kamus Besar Bahasa Indonesia (KBBI) Online, n.d.). Dengan demikian dapat dikatakan kata wadat dan selibat memiliki inti pengertian yang sama yaitu tidak berumah tangga atau tidak melakukan perkawinan. 
Berbicara masalah wadat atau selibat mungkin sedikit sensitif di lingkungan masyarakat Nusantara, meskipun sekali lagi di sekitar kita ada orang-orang yang menjalani hidupnya dengan cara wadat atau selibat. Mengapa perhatian kita arahkan pada sebuah cara hidup yang tidak dijalani oleh banyak orang? Tentu ada banyak alasan yang dapat dikemukakan ketika kita ingin menelisik masalah wadat, namun dalam pembicaraan ini hanya bertujuan mengungkap serba sedikit apa itu wadat agar orang-orang lebih komprehensif dalam memahaminya. Dengan demikian diharapkan dapat menumbuhkan toleransi kita dalam kehidupan bermasyarakat dan berbangsa.

Bagaimana membicarakan masalah wadat tanpa menimbulkan kesensitifan? Kiranya ada banyak cara untuk menjawab pertanyaan tersebut, namun dalam tulisan ini dicoba membicarakannya melalui lakon wayang kulit purwa dan karya sastra epik yang mengemukakan hal wadat tersebut. Pembicaraan itu pun masih dibatasi lagi yaitu menelisik tokoh yang wadat, baik dalam lakon wayang maupun karya sastra epik. Ada dua tokoh yang bersumpah wadat yang dapat ditemukan di dunia pewayangan dan sastra lakon yaitu Lesmana dan Bisma. Namun dalam tulisan ini hanya akan dibicarakan satu tokoh saja yaitu Lesmana. Dalam membicarakan tokoh Lesmana yang wadat ini pun peneliti juga akan membatasi diri dengan hanya mengungkap bagaimana kewadatan Lesmana dipaparkan dalam lakon Banjaran Rahwono Ki Timbul Hadiprayitno, Serat Rama karya Jasadipoera II, dan Novel Anak Bajang Menggiring Angin karya Sindhunata. Selain itu dalam tulisan ini juga akan ditelisik hubungan intertekstual antara ketiga karya tersebut.

\section{Konsep Intertekstual}

Kelahiran suatu karya seni atau karya sastra tidak dapat dipisahkan dari keberadaan karya-karya seni atau karya-karya sastra yang mendahuluinya, yang pernah dicerap oleh sang seniman. Pada mulanya seniman dalam menciptakan karyanya melihat, meresapi, dan menyerap teks-teks lain yang menarik perhatiannya, baik yang dilakukan secara sadar maupun tidak sadar. Ia menggumuli konvensi estetiknya, konvensi sastranya, gagasan yang tertuang dalam karya itu kemudian mentransformasikannya ke dalam suatu karangan, karyanya sendiri (Pradopo, 1987, p. 228). Dalam hal sambutan ini, Teeuw (1983, p. 5) berpendapat bahwa tidak ada suatu karya seni yang berfungsi dalam situasi kosong. Karya seni atau karya sastra merupakan aktualisasi atau realisasi tertentu dari kode sastra dan budaya. Pengarang bebas menerapkan sistem itu secara individual, mengolahnya menurut keperluannya sebagai seniman, atau juga menyimpanginya sesuai dengan kebutuhan yang dikehendakinya. Sebagai akibatnya, audience yang menikmati karya seni atau karya sastra yang baru itu akan merasa terkejut atau terpesona dengan perbedaan yang ditemukannya dari karya seni atau karya sastra yang menjadi hipogramnya. Tegangan itu merupakan aspek hakiki yang sekaligus memainkan peranan penting dalam penikmatan estetik. Hal itu dapat diungkapkan dengan mengacu pada prinsip intertekstualitas (Teeuw, 1988, pp. 367-368).

Dalam ilmu sastra telah dikembangkan berbagai pendekatan untuk penelitian resepsi sastra ialah penelitian bersifat eksperimental, penelitian resepsi lewat kritik sastra dan penelitian resepsi dilihat dari bentuk fisik: intertekstualitas, penyalinan, penyaduran, dan penterjemahan (Teeuw, 1988, pp. 208-217). Intertekstual yaitu resepsi pengarang terhadap teks-teks yang pernah dibacanya dan dilibatkan dalam ciptaannya. Penyaduran adalah pemindahan teks dari satu kode ke kode yang lain yang memperlihatkan satu macam bentuk resepsi. Penerjemahan adalah kegiatan pengalihan teks dari satu bahasa ke dalam bahasa lain yang merupakan satu bentuk sambutan sang penerjemah terhadap teks yang diterjemahkan (Istanti, 2008, p. 29).

Seperti dikatakan di depan bahwa tulisan ini bermaksud mengungkap dan menelisik serta melihat hubungan atau relasi antara lakon Banjaran Rabwono Ki Timbul Hadiprayitno, Serat Rama karya Jasadipoera II, dan Novel Anak Bajang Menggiring Angin karya Sindhunata ketika mengemukakan kewadatan Lesmana. Oleh karena itu konsep intertekstual seperti dikemukakan di muka dipandang cocok untuk digunakan sebagai pisau analisis. 


\section{Kewadatan Lesmana dalam Serat Rama Jasadipoera II}

Ketika kita membaca Serat Rama dapat dikatakan bahwa Jasadipoera mengungkapkan kewadatan dan sumpah wadat Lesmana dengan jelas bahkan ekplisit. Hal ini dapat dibaca pada ририһ VIII bait 9 dan 10, yaitu pada bagian Lesmana digoda wanita cantik jelmaan Sarpakenaka.

(9) Anauri radèn Sumitra tanaya
"Sun iki pindha resi
wadat tanpa krama
sira iku wong apa
warnamu ayu respati
atinggal krama
mengko ta sun tuturi

(10) Umareka marang kadangingsun tuwa manawa ananggapi

ika paranana

Narpa putra Ragawa

pan ingsun tan kena brangti

pan wus ubaya

lawan Bathara luwih.

(Jasadipoera, 1925, p. 26)

Terjemahan:

(“..... (9) Raden Sumitra tanaya (Lesmana) menjawab aku ini seorang resi yang bersumpah wadat tidak akan beristeri, engkau ini siapa, wanita cantik tetapi tidak tahu tata krama, tolong dengarkan akan kuberi tahu, // (10) mendekatlah ke tempat kakakku mungkin dia akan menerimamu, ke sana hampirilah Ragawa, sebab aku tidak boleh jatuh hati, sebab aku telah bersumpah kepada Dewata yang Agung')

Dalam penceritaan tentang tokoh Lesmana, Jasadipoera tidak mengemukakan mengapa Lesmana wadat dan kapan sumpah wadatnya itu diucapkan dalam pupuh-pupuh sebelumnya. Dia hanya mengemukakan bahwa Lesmana adalah seorang resi yang wadat dan telah mengucapkan sumpah wadat kepada bathara, seperti dapat dibaca dalam petikan teks di atas.

Selain pada pupuh VIII: 9, 10, kewadatan Lesmana juga dapat dilihat pada pupuh X: 14-17, yaitu saat ia diminta oleh Sinta menyusul Rama ke dalam hutan. Dia sudah berjanji kepada kakaknya akan menjaga keselamatan Sinta, maka dia tidak bersedia meluluskan permintaan Sinta itu. Pada bagian ini diungkapkan ujian mental bagi seorang yang menjalani wadat. Sinta menuduh Lesmana tidak mau menuruti perintahnya karena dia mempunyai maksud tersembunyi yaitu menginginkan Rama mati. Dengan matinya Rama, maka ia akan mudah memperisteri Sinta. Mendapat tuduhan itu Lesmana tersentuh harga dirinya sebagai seorang yang menjalani wadat, lalu ia pergi sambil mengucapkan sapata 'kutukan' untuk Sinta, bahwa kelak Sinta akan ditawan oleh musuh. Sapata ini pun terwujud karena Sinta kemudian diculik Rawana setelah ditinggal pergi Lesmana. Peristiwa ini dapat dibaca sebagai penegasan terhadap penokohan Lesmana sebagai seorang resi yang menjalani wadat. Sehingga ucapannya atau sapatanya menjadi kenyataan. Petikan teks-teks Serat Rama berikut menunjukkan hal tersebut.
(14) Sukur Ragawa matia
Sun gumantya ing rabiné
Angajab drubaka sira
Lumub ing pakoningwang
Pan ingsun ubaya tumub:
Matia Ramawijaya

(15) Tan anyipta kerama malih

Aturun geni kéwala

Yèn Raguputra patiné

Kenaa ing kidang emas

Sun pedhot guluningwang

Manjinga ing geni murub

Mangsa ngawula ing sira

(16) Sumitra tanaya sedhih

Tyasira pinaribawa:

"Tawata ngawiyat kabèh

Tedhaka aneksènana

Duwéa cipta ala

Narakaa satus èwu”

Mangkat angusapi waspa

(17) Garundelan anèng margi:

"Muga tinawana mengsah

Ing mengko sawuriningong

Déné ta nora kajamak.

Geter lor wétan ngakak

Wiku tyas Laksmana wiku 
Napata wus nusul tebah

(Jasadipoera, 1925, p. 26)

Terjemahan:

(“.... (hatimu berkata: Sukurlah kalau Rama mati, aku akan mengawini isterinya. Kamu sangat jahat tidak mau melakukan apa yang kuminta. Aku telah bersumpah bila Ramawijaya mati, aku tidak akan menikah lagi. Aku akan melakukan patibrata 'kesetiaan pada suami', menceburkan diri ke dalam api suci, aku tidak sudi menjadi isterimu. Lesmana sedih, dan agak tersinggung sehingga di dalam hati ia berucap: "Wahai para dewa di langit turunlah untuk menjadi saksi, jika aku mempunyai niat jahat maka hukumlah aku tempatkan aku di neraka. Lesmana lalu pergi dengan hati yang terluka. Dalam perjalanan ia berucap semoga (Sinta) ditawan oleh musuh setelah kepergianku. Semesta bergetar mendengar sapata sang wiku Lesmana”).

\section{Kewadatan Lesmana dalam Novel Anak Bajang Menggiring Angin Karya Sindhunata}

Sindhunata mengungkapkan bahwa novelnya ini ditulis sebagai hasil bacanya terhadap teks sastra dan pertunjukan yang menceritakan kisah Rama-Sinta, dan tentu juga Lesmana. Jika teks dalam novel ini kita baca yaitu bagian peristiwa Lesmana digoda perempuan cantik, dapat dikatakan ada kedekatan dengan Serat Rama yang telah dibicarakan di depan. Dalam peristiwa itu Lesmana mengatakan bahwa dirinya menjalani wadat, tidak akan kawin seumur hidup. Berikut petikan teksnya:

"Hai perempuan, maafkanlah aku. Aku sudah berjanji tidak akan kawin seumur hidupku, disaksikan asap kurban purnama sidhi, aku berkaul untuk hidup wadat" (Sindhunata, 1983, p. 108).

Kewadatan Lesmana yang lain juga dapat kita temukan dalam novel ini yaitu dalam peristiwa terusiknya harga diri Lesmana sebagai orang yang menjalani wadat, ketika dituduh mempunyai maksud tersembunyi atas penolakannya akan permintaan Sinta. Dalam peristiwa itu ia menjelaskan arti sumpah wadat kepada Sinta. Dalam peristiwa itu, meski tidak secara eksplisit memperlihatkan adanya kutukan Lesmana kepada Sinta, namun dalam novel ini kita dapat membaca bahwa Lesmana di dalam diamnya (di dalam hatinya) ia mengucapkan sapata. Dalam novel Anak Bajang Menggiring Angin ini tidak disebutkan sumpah wadat Lesmana di depan Sinta, namun disebutkan bahwa janji wadat sudah dilakukannya sebelum dirinya dituduh menginginkan Sinta. Petikan teks berikut menceritakan tentang kewadatan Lesmana.

" Sinta kakakku, sejak muda aku telah berjanji untuk hidup wadat. Mungkin aku bisa mengkhianati kakakku, tapi aku pasti tak akan mengkhianati diriku sendiri. Aku takkan ingkar dari janji masa mudaku. Oh, dewa, segala isi dunia tahu, sehingga dunia takkan rela membiarkan aku dituduh demikian. Aku diam, tetapi dunialah yang akan membalaskan orang yang berlaku tidak adil kepadaku," kata Laksmana menatap langit (Sindhunata, 1983, p. 120).

\section{Kewadatan Lesmana dalam Lakon Banjaran Rahwono Ki Timbul Hadiprayitna}

Dalam lakon Banjaran Rabwono Ki Timbul Hadiprayitno, kewadatan Lesmana dapat dilihat dalam dua adegan. Yang pertama, dalam adegan Lesmana digoda Endhang Sapanyana, kedua adegan Lesmana dituduh hendak menginginkan Sinta. Dalam adegan Lesmana digoda Endhang Sapanyana, Ki Timbul Hadiprayitno menceritakan kewaspadaan dan keteguhan hati Lesmana. Berikut petikan kandha mengenai hal itu.

"Raden Lesmana dupi caket kaliyan ingkang ngaken Endhang Sapanyana, wus datan kesamaran bilih sejatosipun punika panggirigodha. Sedya mrepegi dyan Lesmana, sedya nggrayang angganipun dyan Lesmana. Nanging, dèn rumiyini déning Radèn Lesmana, dipunpithes grananipun, sanalika pindha pinugut, badhar sejatining wujud dèwi Sarpa Kenaka, bertèk-bertèk."

(Hadiprayitna, 2012)

Terjemahan:

(Ketika Lesmana dekat dengan orang yang mengaku Endhang Sapanyana, ia sangat 
yakin bahwa ini merupakan godaan. Dia hendak mendekati Lesmana dan hendak meraba tubuh Lesmana, tetapi terlambat, Lesmana telah berhasil mithes "ditekan dan dijepit dengan jari telunjuk dan ibu jari' hidung wanita tersebut hingga terputus. Berubahlah ia pada wujud aslinya yaitu Dewi Sarpakenaka. Sang dèwi pun berteriak-teriak).

Dalam kandha itu Ki Timbul Hadiprayitno belum tampak secara eksplisit menyebut Lesmana sebagai ksatria yang selibat. Di situ Lesmana baru digambarkan sebagai seorang kesatria yang teguh hati, bermartabat, dan menjaga kemurnian dirinya. Dapat dikatakan dalam adegan itu baru muncul bibit kewadatan Lesmana.

Kewadatan Lesmana baru dikemukakan secara ekplisit oleh $\mathrm{Ki}$ Timbul Hadiprayitno dalam adegan Sinta menuduh Lesmana menginginkan dirinya. Berikut petikan teksnya:

'Kangmbok, menawi panjenengan maiben, kula aturi neksèni, kula menika satriya kangmbok. Satriya punika mboten kalih tiga wecanipun. Kula aturi neksèni lan jagat sakisinipun aneksènana, Lesmana saklaminipun mboten badhé cerak kaliyan wanodya, sumedya nglampabi wadat".

(Hadiprayitna, 2012)

Terjemahan:

('Kanda Dewi, apabila engkau tidak percaya, jadilah saksi, aku ini ksatria Kanda. Satria itu tidak berubah-ubah keputusannya. Kuminta Kanda Dewi menjadi saksinya dan semesta ini juga menjadi saksi, Lesmana selamanya tidak akan dekat dengan wanita, hendak menjalani hidup wadat')

Dalam adegan ini, Ki Timbul Hadiprayitno baru memunculkan kewadatan Lesmana, yaitu lewat sumpah untuk hidup wadat yang diucapkannya.

\section{Dinamika Kewadatan Lesmana dalam Bingkai Intertekstual}

Sumpah wadat Lesmana merupakan salah satu bagian dari dinamika kehidupannya. Namun demikian, sebenarnya ada banyak dinamika yang menyertai pejalanan kehidupan Lesmana sebelum dirinya mengikrarkan sumpah agung itu. Dinamika-dinamika itulah yang menjadi gambaran proses menuju puncak tataran kehidupannya sebagai seorang brahmacari 'seseorang yang berfokus pada pendidikan (belajar ilmu pengetahuan dan teknologi) dan dia harus selibat'.

Peristiwa sumpah wadat Lesmana tidak terjadi begitu saja atau secara tiba-tiba. Tetapi, ada dinamika dan proses yang dijalani dalam kehidupannya. Ada berbagai versi yang menyebutkan peristiwa sumpah dan latar belakang sumpah Lesmana. Ada yang mengungkapkan secara jelas bahwa Lesmana melakukan tindakan memotong alat vitalnya atau baymwara ketika selesai bersumpah (Senawangi, 1999, pt. 831). Ada pula yang hanya meninggalkan Sinta. Tetapi, ada juga mengatakan bahwa Lesmana garundelan aneng margi 'di jalan bergumam karena kecewa' sambil mengutuk Sinta agar tertangkap musuh (Jasadipoera, 1925, p. 32).

Ungkapan mengenai latar belakang terjadinya sumpah wadat Lesmana juga bervariasi. Ada yang beranggapan bahwa Lesmana ingin membuktikan ketulusannya di hadapan Sinta. Ada juga yang menyebutkan bahwa penyebabnya adalah kutukan dari Sarpakenaka yang hasrat kebirahiannya ditolak oleh Lesmana (Sujarwo \& dkk, 2010, p. 361).

Tiga karya yang telah disebutkan di depan yaitu lakon Banjaran Rahwono Ki Timbul Hadiprayitno, Serat Rama karya Jasadipoera II, dan Novel Anak Bajang Menggiring Angin karya Sindhunata setelah dibaca menampakkan kesamaan, perbedaan, dan relasi proses kewadatan Lesmana. Oleh karena itu melalui tiga karya tersebut akan ditelisik mengenai peristiwa sumpah wadat dan latara belakang wadat Lesmana. Atau dengan kata lain akan dilihat dinamika kewadatan Lesmana.

Teks Serat Rama digubah oleh R. Ng. Jasadipoera seorang pujangga dari Surakarta (1729 - 1802). Pengantar dari teks ini diberikan oleh J. Kats. Teks Serat Rama diterbitkan oleh Bale Poestaka di Weltevreden (sekarang Jakarta) pada tahun 1925. Teks ini terdiri dari jilid I dan 
jilid II. Adapun yang memuat seputar kehidupan selibat Lesmana terdapat di jilid II.

Novel Anak Bajang Menggiring Angin merupakan karya dari Dr. Gabriel Possenti Sindhunata, S.J. Sindhunata adalah seorang imam Jesuit kelahiran Malang Jawa Timur pada $12 \mathrm{Mei}$ 1952. Novel ini ditulis oleh Sindhunata sekitar dua tahun lamanya. Novel ini diberi judul Anak Bajang Menggiring Angin dengan alasan filosofis. Sindhunata menggambarkan bahwa anak bajang yang tak ubahnya seperti makhluk yang tidak sempurna, namun mendambakan kesempurnaan. Sebaliknya dengan manusia yang sempurna, ternyata sering tidak menghargai kesempurnaan yang ia miliki. Kisah wayang dalam bentuk sastra dirasakan oleh Sindhunata sebagai sesuatu yang terasa monoton dan kurang menarik. Maka, ia kemudian tergerak untuk menuliskannya semenarik mungkin dan lebih inspiratif. Sindhunata merasa dituntun oleh inspirasi dan imajinasi serta dengan seluruh pergulatan hidupnya (Sindhunata, 2017).

Lakon Banjaran Rabwono merupakan karya $\mathrm{Ki}$ Timbul Hadiprayitno yang disajikan berdasarkan tradisi lisan yang dihidupinya dan juga dari hasil bacanya terhadap teks-teks sastra yang berkaitan dengan kisah Rahwana. Ki Timbul Hadiprayitna telah berpengalaman dalam mempergelarkan lakon-lakon Banjaran. Dalang ini mengungkapkan bahwa hampir semua lakon banjaran ia ciptakan kembali serta direka dari sumber baik tertulis maupun lisan atau yang biasa disebut lakon-lakon padhalangan (Hadiprayitno, 2017, p. 108).

Guna mempermudah dalam memahami kehidupan wadat Lesmana, maka penulis membuat tiga bagian tahapan yaitu bagian awal, bagian tengah, dan bagian akhir. Pada setiap bagian mengungkapkan dinamika dan jatidiri Lesmana sebagai pribadi yang menjalani kehidupan wadat. Dinamika kewadatan Lesmana yang telah dibagi menjadi tiga tahap kemudian dikemukakan dalam bentuk tabel sebagai berikut.

Tabel 1. Perbandingan bagian awal seputar dinamika kewadatan Lesmana
Bagian Awal

\begin{tabular}{|c|c|c|c|}
\hline \multicolumn{2}{|r|}{ Teks Serat Rama } & $\begin{array}{c}\text { Novel Anak } \\
\text { Bajang Menggiring } \\
\text { Angin }\end{array}$ & $\begin{array}{c}\text { Lakon Banjaran } \\
\text { Rabwono Ki } \\
\text { Timbul HP }\end{array}$ \\
\hline & $\begin{array}{l}\text { Wanita cantik } \\
\text { bagai bidadari } \\
\text { jatuh cinta pada } \\
\text { Laksmana } \\
\text { (Jasadipoera, } \\
\text { 1925, p. 26). }\end{array}$ & $\begin{array}{l}\text { 1. Wanita } \\
\text { penggoda } \\
\text { meminta } \\
\text { Laksmana } \\
\text { agar } \\
\text { melindungi- } \\
\text { nya } \\
\text { (Sindhunata, } \\
\text { 1983, p. } \\
\text { 108). }\end{array}$ & $\begin{array}{l}\text { 1. Lesmana } \\
\text { yang sedang } \\
\text { semadi } \\
\text { didatangi } \\
\text { Endang } \\
\text { Sapanyana } \\
\text { yang } \\
\text { membangun } \\
\text {-kannya. }\end{array}$ \\
\hline 2. & $\begin{array}{l}\text { Laksmana } \\
\text { mengungkapka } \\
\mathrm{n} \text { jati dirinya } \\
\text { saat digoda } \\
\text { oleh wanita } \\
\text { tersebut, } \\
\text { katanya: } \\
\text { pindha iki resi , } \\
\text { wadat tanpa } \\
\text { krama } \\
\text { (Jasadipoera, } \\
\text { 1925, p. 26). }\end{array}$ & $\begin{array}{l}\text { 2. Laksmana } \\
\text { mengungka } \\
\text { pkan jati } \\
\text { diri-nya } \\
\text { yang sudah } \\
\text { tidak akan } \\
\text { kawin } \\
\text { seumur } \\
\text { hidup pada } \\
\text { wanita } \\
\text { penggoda } \\
\text { tersebut } \\
\text { (Sindhunata } \\
\text { 1983, p. } \\
\text { 108). }\end{array}$ & $\begin{array}{l}\text { 2. Endang } \\
\text { Sapanyana } \\
\text { nyandra } \\
\text { sarandhuning } \\
\text { badan } \\
\text { Lesmana } \\
\text { sebagai } \\
\text { gambaran } \\
\text { ketertarikan } \\
\text { nya pada } \\
\text { fisik } \\
\text { Lesmana } \\
\text { yang } \\
\text { membangkit } \\
\text { kan gairah } \\
\text { seksual. }\end{array}$ \\
\hline
\end{tabular}

3. Laksmana menolak Sarpakenaka yang berubah cantik dengan memberikan alternatif lain yaitu supaya menghadap Rama (Jasadipoera, 1925, p. 26).

3. Endang Sapanyana ngunggahunggabi Lesmana atau hendak sumita yang disertai ancaman bunuh diri apabila ia ditolak.

4. Endang Sapanyana menawarkan diri untuk melayani hubungan seksual kepada Lesmana dengan berkata: "Mangga kula ladosi Radèn." 
Tabel 2. Perbandingan bagian tengah seputar dinamika kewadatan Lesmana

Bagian Tengah

\begin{tabular}{|c|c|c|}
\hline Teks Serat Rama & $\begin{array}{c}\text { Novel Anak } \\
\text { Bajang } \\
\text { Menggiring } \\
\text { Angin }\end{array}$ & $\begin{array}{c}\text { Lakon } \\
\text { Banjaran } \\
\text { Rabwono Ki } \\
\text { Timbul HP }\end{array}$ \\
\hline $\begin{array}{l}\text { 1. Laksmana } \\
\text { mengungkap-kan } \\
\text { kembali } \\
\text { kewadatannya } \\
\text { yang kedua } \\
\text { dengan } \\
\text { ungkapan: } \\
\text { Pan ingsun tan kena } \\
\text { brangti, pan wus } \\
\text { ubaya, lawan } \\
\text { Bathara luwih } \\
\text { (Jasadipoera, } \\
\text { 1925, p. 26). }\end{array}$ & $\begin{array}{l}\text { 1. Laksmana } \\
\text { dipeluk } \\
\text { dan } \\
\text { direbahka } \\
\text { n oleh } \\
\text { wanita } \\
\text { penggoda } \\
\text { (Sindhun } \\
\text { ata, 1983, } \\
\text { p. 109). }\end{array}$ & $\begin{array}{l}\text { 1. Lesmana } \\
\text { ter-bangun } \\
\text { dari } \\
\text { semadinya } \\
\text { dan } \\
\text { kesadaran } \\
\text { nya } \\
\text { terbuka, } \\
\text { dan ia tahu } \\
\text { bahwa } \\
\text { wanita ini } \\
\text { adalah } \\
\text { penggoda. }\end{array}$ \\
\hline $\begin{array}{l}\text { 2. Sarpakenaka } \\
\text { mendekati } \\
\text { Laksmana tak } \\
\text { ubahnya seperti } \\
\text { isteri yang penuh } \\
\text { asmara. Namun, } \\
\text { Laksmana segera } \\
\text { bertindak dengan } \\
\text { memelintir } \\
\text { hidungnya hingga } \\
\text { putus } \\
\text { (Jasadipoera, } \\
\text { 1925, p. 27). }\end{array}$ & $\begin{array}{l}\text { 2. Laksmana } \\
\text { menarik } \\
\text { hidung } \\
\text { wanita } \\
\text { tersebut } \\
\text { hingga } \\
\text { putus lalu } \\
\text { berubah } \\
\text { menjadi } \\
\text { Sarpake- } \\
\text { naka } \\
\text { (Sindhun } \\
\text { ata, 1983, } \\
\text { p. 109). }\end{array}$ & $\begin{array}{l}\text { 2. Endang } \\
\text { Sapanyana } \\
\text { hendak } \\
\text { menjamah } \\
\text { tubuh } \\
\text { Lesmana. }\end{array}$ \\
\hline
\end{tabular}

3. Lesmana mengambi 1 tindakan dengan mithes hidung wanita penggoda tersebut sampai putus.

4. Sarpa

kenaka meninggalkan Lesmana dengan disertai ancaman.
Tabel 3. Perbandingan bagian akhir seputar dinamika kewadatan Lesmana

Bagian Akhir

\begin{tabular}{l} 
Teks Serat Rama \\
\\
\hline 1. Regawa \\
meninggalkan \\
Sinta dan \\
Laksmana \\
(berdua) di \\
pertapan untuk \\
menangkap kijang \\
Jasadipoera, \\
1925, p. 31). \\
2. Laksmana \\
mengungkap-kan \\
kekecewaan \\
hatinya terhadap \\
Sinta yang \\
menuduhnya \\
macam-macam \\
(Jasadipoera, \\
1925, p. 31). \\
3. Ia berucap dalam \\
hati "Dewata \\
menjadi saksi, bila \\
aku punya niat \\
jahat masuklah ke \\
neraka" \\
(Jasadipoera, \\
1925, p. 32). \\
\end{tabular}

$\begin{array}{ll}\text { Novel Anak } & \text { L } \\ \text { Bajang Menggiring } & \text { B } \\ \text { Angin } & R\end{array}$

Lakon

Banjaran

Rabwono Ki

Timbul HP

1. Sinta 1. Lesmana

menuduh

Laksmana

akan

melampiaskan

nafsunya

dan Sinta di

tinggal

Rama untuk

kepada dirinya

(Sindhunata,

1983, p. 118).

2. Laksmana mengungkapk an kepada mencari kijang

kencana.

Sinta bahwa dirinya sudah berjanji wadat sejak muda

(Sindhunata, 1983, p. 120).

2. Lesmana dituduh oleh Sinta bahwa ia menginginka n dirinya

3. Lesmana melakukan sumpah wadat di depan Sinta sebagai bukti bahwa ia tidak ada maksud untuk menikahinya/ngalab.

4. Namun demikian, ia dengan gerundelan, yang isinya semacam mengutuk Sinta supaya tertangkap musuh Jasadipoera, 1925, p. 32).

4. Sumpahnya tidak dipercaya oleh Sinta. Maka, ia akhirnya menerima permintaan Sinta untuk mencari

Rama, namun terlebih dahulu ia membuat ubengan sadhepa agar Sinta terjaga keselamatan -nya. 
5. "Wiku tyas

Laksmana wiku"

sebagai ungkapan

penulis untuk

menerangkan

Laksmana yang

berhati wiku

(Jasadipoera,

1925 , p. 32).

Berdasarkan tabel di atas dapat dikatakan bahwa tantangan hidup wadat itu bertahap mulai dari ranah penglihatan, verbal lalu ke ranah fisik dan selanjutnya ke ranah harga diri yang terdalam. Berkaitan dengan kontinuitas dan diskontinuitas perjalanan sebuah kisah epik baik dalam bentuk tulis maupun lisan, dalam tiga teks yang dihadirkan dalam tulisan ini dapat dikatakan kewadatan Lesmana tidak mengalami penyimpangan atau perubahan. Ketiga-tiganya menceritakan bahwa Lesmana memang menjalani hidup selibat.

\section{Simpulan}

Tulisan ini menghasilkan temuan berupa konsep kewadatan Lesmana dalam teks tulis (Serat Rama Jasadipoera II dan Novel Anak Bajang Menggiring Angin karya Sindhunata) dan teks lisan pertunjukan (lakon Banjaran Rabwono Ki Timbul Hadiprayitno). Ketiga teks yang memuat tentang kewadatan Lesmana ini berasal dari zaman yang berbeda. Setelah ditelisik ternyata kewadatan Lesmana dari waktu ke waktu dalam ketiga teks tidak mengalami penyimpangan atau perubahan. Atau dengan kata lain konsep kewadatan Lesmana dipertahankan secara kontinyu.

\section{Kepustakaan}

Hadiprayitna, K. T. (2012). Ki Timbul Hadiprayitno Banjaran Rabwono 07. https://www.youtube.com/watch?v $=5 \mathrm{dYz}$ F-uSsaQ

Hadiprayitno, K. (2017). Estetika Pedalangan Ruwatan Murwakala Kajian Estetika dan Etika Budaya Jawa. BP ISI Yogyakarta.

Istanti, K. Z. (2008). Sambutan Hikayat Amir Hamzah dalam Sejarah Melayu, Hikayat Umar Umayah, dan Serat Menak. Seksi Penerbitan
Fakultas Ilmu Budaya UGM.

Jasadipoera. (1925). Serat Rama Jilid II. Bale Poestaka.

Kamus Besar Bahasa Indonesia (KBBI) Online. (n.d.). Retrieved December 23, 2020, from https://kbbi.web.id/buku.html

Poerwadarminta, W. J. S., \& dkk. (1939). Baoesastra Djawa. J.B. Wolters' Uitgevers Maatschappij Groningen.

Pradopo, R. D. (1987). Pengkajian Puisi. Gadjah Mada University Press.

Senawangi, T. (1999). Ensiklopedi Wayang Indonesia. Tim Senawangi.

Sindhunata. (1983). Anak Bajang Menggiring Angin. Gramedia.

Sujarwo, H., \& dkk. (2010). Rupa dan Karakter Wayang Purwa. Kaki Langit Kencana Prenada Media Group.

Teeuw, A. (1983). Membaca dan Menilai Sastra. Gramedia.

Teeuw, A. (1988). Sastra dan Ilmu Sastra. Pustaka Jaya. 